\title{
Propranolol Therapy for an Abdominal Giant Haemangioma in a Neonate
}

\author{
Docx $M \mathrm{MF}^{1}$, Vandenberghe $\mathrm{P}^{2}$, Van De Broek ${ }^{3}$, Govaert $\mathrm{P}^{3}$
}

\begin{abstract}
A one day old Moroccan boy was admitted to our neonatal unit with a giant tuberous right abdominal haemangioma. The clinical examination revealed no other vascular tumours. There was no evidence of heart failure. Ultrasound and MRA documented a giant vascular structure suggestive of haemangioma. The tumor responded well to propranolol treatment.
\end{abstract}

Key words: Haemangioma, Giant tuberous haemangioma

\section{Introduction}

nfantile haemangioma are benign vascular tumours, most of which resolve spontaneously and do not require treatment. Treatment is only indicated when complications are expected like impairment of vital functions by ocular or airway involvement, and secondly in cases where the haemangioma cause significant bleeding by friction, ulceration and disfigurement. An increasing incidence with decreasing gestational age is described: $1-4 \%$ in term infants to $23 \%$ in those with a birth weight $<1000 \mathrm{~g}^{1}$. The serendipitous discovery in 2008 of propranolol, a non selective beta-adrenergic antagonist and a few years later the topical variant timolol maleate $0.5 \%$, has become the first-line therapy for complicated haemangioma ${ }^{2}$. The latter resulted in a rapid replacement of oral steroids, laser surgery, interferon and vincristine treatment.

The present case is a 1-day-old boy who presented to our neonatology department with a huge tuberous haemangioma of the entire right lower abdomen. After relevant investigations we decided to start oral propranolol therapy to prevent ulceration and disfigurement.

\section{The Case}

An one day of age a Moroccan boy was admitted to our neonatal unit with a diagnosis of giant tuberous right abdominal haemangioma. The clinical examination revealed no other vascular tumours. There was no evidence of heart failure. Ultrasound and MRA (Fig 1a-b) documented a giant vascular structure compatible with haemangioma and with the following measurements: laterolateral diameter: $7 \mathrm{~cm}$, anteroposterior diameter: $1.2 \mathrm{~cm}$ and craniocaudal diameter: $4 \mathrm{~cm}$. The feeding vessel was the right common femoral artery and draining happened via the right common
'Docx MKF, Department of Paediatric Chronic Diseases and Hypertension, Queen Paola Children's Hospital Antwerp Belgium, '2Vandenberghe $\mathrm{P}$, Department of Paediatric Cardiology, Queen Paola Children's Hospital Antwerp, Belgium, ${ }^{3}$ Van de Broek, Department of Neonatology, General Hospital Middelheim, Antwerp, Belgium, ${ }^{4}$ Govaert P, Department of Neonatology, General Hospital Middelheim Antwerp, Belgium.

Address for correspondence:

Dr. Martine KF Docx

E-mail: docxmartine@skynet.be

\section{How to cite}

Docx MKF, Vandenberghe P, Van De Broek, Govaert P. Propranolol Therapy for an Abdominal Giant Haemangioma in a Neonate. J Nepal Paediatr Soc 2015;35(2):189-191.

doi: http://dx.doi.org/10.3126/jnps.v35i2.13877

This work is licensed under a Creative Commons Attribution 3.0 License.

\section{(c) (i)}

femoral vein. According to protocol for giant haemangioma we started with propranolol treatment at the age of three weeks. Baseline echocardiography together with a 12 lead ECG and 72-hr hospitalisation was done to monitor vital signs and blood glucose levels. The results were normal. Propranolol was gradually tapered over a period of 2 weeks started with an initial dose of $0.16 \mathrm{mg} / \mathrm{kg}$ body weight to up a maximum daily dose of $2 \mathrm{mg} / \mathrm{kg}$ (Fig 2). There were no side effects. A re-evaluation after 7 days and then every month was done. We re-visualised the lesion with MRA after four months of treatment, supplemented with monthly photographic documentation, clinical examination and ultrasound. (Fig 3-4) 

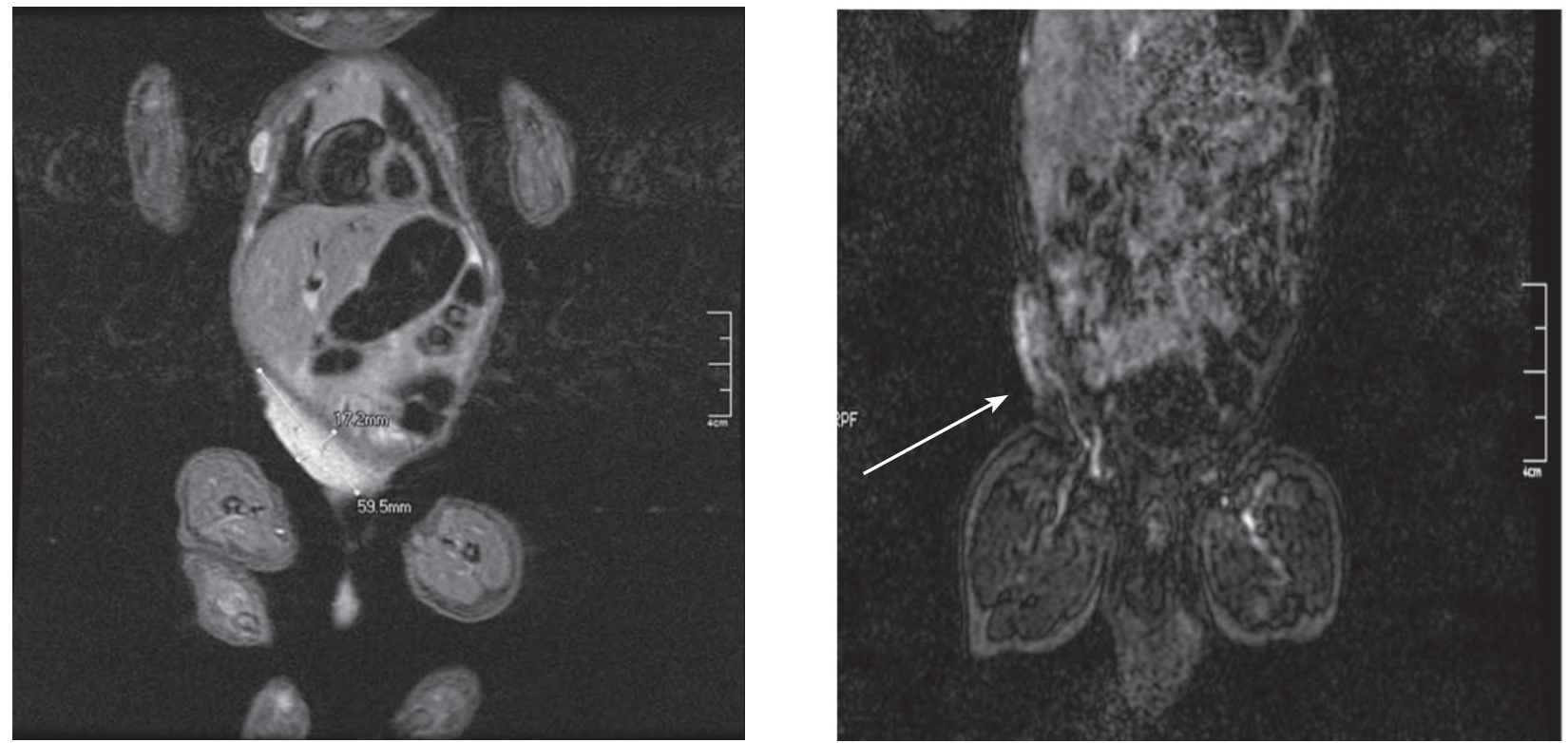

Fig 1: a-b: MRA:Giant vascular structure. Fig. 1-b: Feeding vessel was the right common femoral artery and draining happened via the right common femoral vein (white arrow).

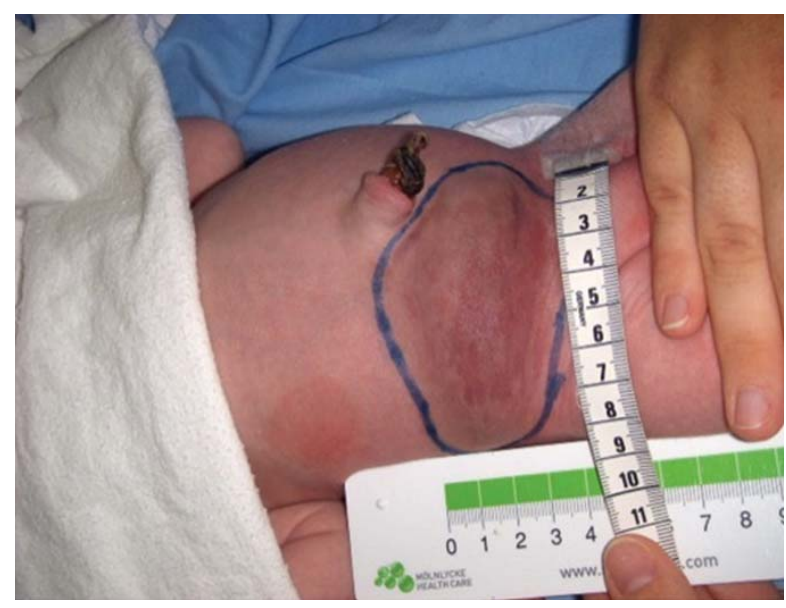

Fig 2: Size of lesion after treatment with Propranolol (2 $\mathrm{mg} / \mathrm{kg} /$ day) orally.

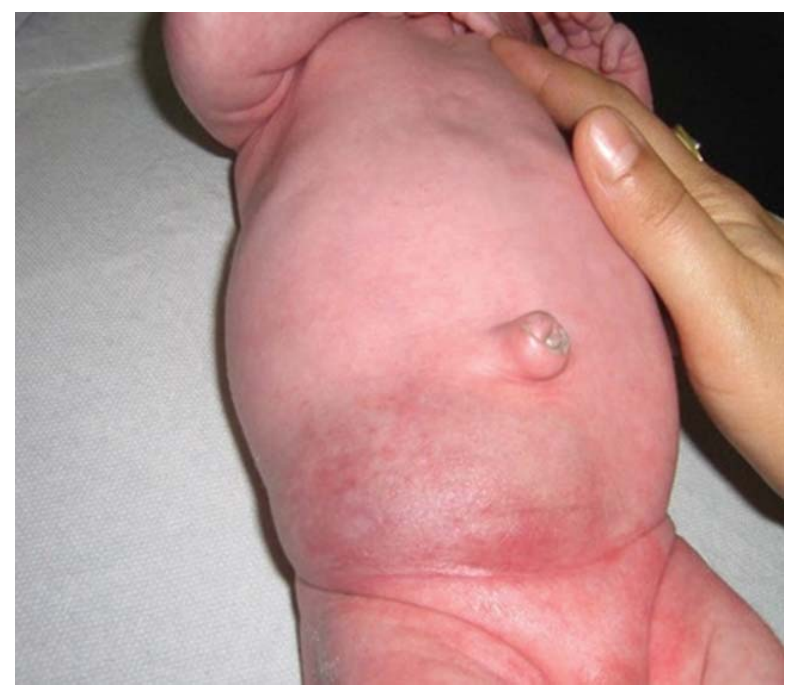

Fig 3: Regression of size after nearly 4 months treatment.

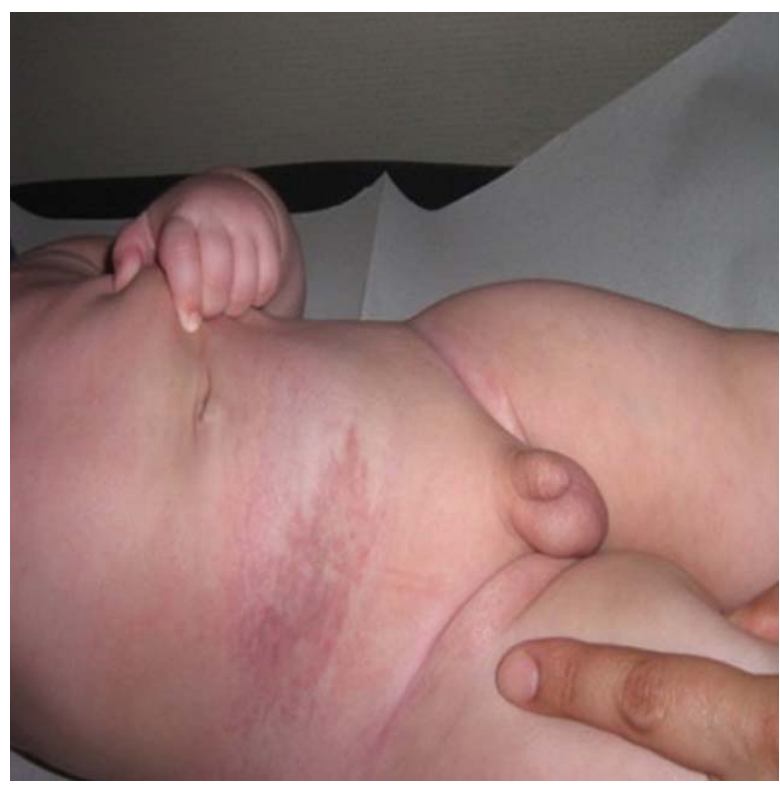

Fig 4: Minimal lesion after nearly 8 months of treatment.

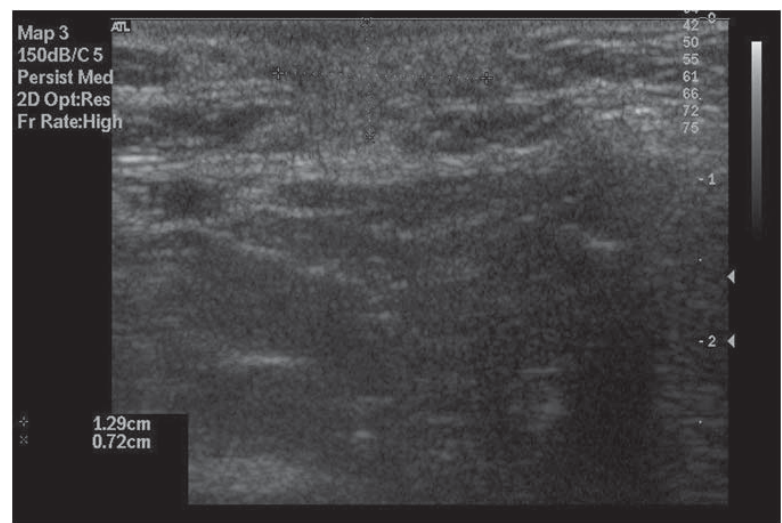

Fig 5: Ultrasound of the lesion after 8 months therapy. 
The volume had strikingly diminished after eight months therapy. Ultrasound of the lesion (Fig. 5): the craniocaudal diameter: $1.29 \mathrm{~cm}$ (max.) and $0.72 \mathrm{~cm}$ (min.).

\section{Discussion}

Haemangiomas are the most common tumours of infancy, especially in Caucasians, affecting up to $12 \%$ of all children, occurring more frequently in girls with a sex ratio of $3: 1.60 \%$ Of infantile haemangiomas are located in the head and neck region, $80 \%$ are single lesions $2,4,7$. They undergo rapid and intermittent growth throughout the first year of life. By the age of nine years $90 \%$ of the lesions have involuted, but nevertheless in $50 \%$ a residue can be observed (teleangiectatic cutaneous vessels, fibrous-fatty tissue, scar formations). There are different theories on the origin of infantile haemangioma. These include suggestions of placental origin, intrinsic defect or somatic endothelial mutation, and extrinsic factors creating a conductive milieu for growth.

Three hypotheses for the beneficial effect of propranolol have been described ${ }^{3,6,7}$ :-

Vasoconstriction and thus almost immediate change and softening of the lesions; cells;

Triggering of apoptosis of capillary endothelial

Decreased expression of vascular endothelial growth factor (VEGF) and basic fibroblast growth factor (bFGF) genes through downregulation of the RAFmitogen activated protein kinase pathway.

Most haemangiomata require no treatment, but it is imperative if dramatic aesthetic, and/or functional impairment, like visual or airway obstruction or ulceration arises ${ }^{7}$. The response of infantile haemangioma to propranolol was published by LéautéLabrèze et. al. 4,5,6.

\section{Conclusion}

Propranolol is effective and safe for treating with a minimal dose to achieve involution of $2 \mathrm{mg} / \mathrm{kg} / \mathrm{d}$. Treatment should only be reserved for lesions resulting in significant morbidity/mortality and disfigurement. The duration of the treatment should be maintained until the lesion is involuted with an acceptable cosmetic result.

\section{References}

1. Goelz R, Poets CF. Incidence and treatment of infantile hemangioma in preterm infants. Arch Dis Child Fetal Neonatal Ed 2015; 100(1): F 85-91.

2. Buckmiller LM, Munson PD, Dyamenahalli U, Dai Y, Richter GT. Propranolol for Infantile Hemangiomas: Early Experience at a Tertiary Vascular Anomalies Center. Laryngoscope 2010;120(4):676-681.

3. Dubois J, Alison M. Vascular anomalies: what a radiologist needs to know. Pediatr Radiol 2010;40:895-905.

4. Lawley LP, Siegfried E, Todd JL. Propranolol Treatment for Hemangioma of Infancy: Risks and Recommendations. Pediatr Dermatol 2009;26(5):610-14.

5. Löffler H, Kosel C, Cremer H, Kachel W. Propranolol therapy to treat problematic hemangiomas: a new standard therapy makes its debut. Hautartz 2009;60(12):1013-1016.

6. Sans V, Dumas de la Roque E, Berge J, Grenier N, Boralevi F, Mazereeuw-Hautier J, Lipsker D, Dupuis $E$, Ezzedine $K$, Vergnes $P$, Taïb $A$, Léauté-Labrèze C. Propranolol for Severe Infantile Hemangiomas: Follow-Up Report. Pediatrics 2009;124;e423-e431.

7. Zimmermann AP, Wiegand S, Werner JA, Eivazi B. Propranolol therapy for infantile haemangiomas: Review of the literature. Int $J$ Pediatr Otorhinolaryngol 2010;74(4):338-42. 